\title{
CORRESPONDENCE
}

\section{INTRACAPSULAR CATARACT OPERATION}

\section{To the Editorial Committee of the British Journal of OphthalmologY}

SiRs-The recent article by Nirankari and Maudgal (1957) entitled "A Modification of the Smith Indian Technique of Intracapsular Cataract Operation" brings forth a very important point in modern cataract technique. This is a method of using extraction technique without a vitreous wedge, counter pressure being used only on the anterior segment of the eyeball and anterior to the vitreous.

No mention is made in this paper of pre-operative pressure on the eyeball. If pressure is exerted upon the eyeball for 5 minutes just before the operation, hypotony is usually obtained. With such hypotony the method described by these authors from India would not be applicable, as counter pressure above would not tilt the lens upwards from below to the degree desired.

As described by Harrington (1951), and stressed by the present writer (Hill, 1957), if the erisophake is used to lift the lower pole of the lens upwards, counter pressure can be placed higher up on the anterior segment-namely at the limbus or even anterior to the limbus. By this technique the pressure is farther forwards from the vitreous face, and counter pressure may be used to strip the tensed zonule from the capsule and the lens may be tumbled more easily and safely. The erisophake, if left in place on the capsule for 20 seconds, moulds the capsule into the cup - tensing the zonule fibres evenly along the circumference. The counter pressure is thereby more efficient in stripping away the attachment of the zonule to the anterior capsule and folding the cornea under the lens.

It is realized that the methods used in the large clinics of India involve a time element not considered in Western procedures, but the time consumed in placing the erisophake upon the lens for 20 seconds, which gives an added element of safety and further prevention of vitreous loss, is worth consideration. If necessary, this 5 minutes of pre-operative pressure may be exerted by a nurse or trained assistant.

Yours faithfully, HowARD F. HILL.

33 College Avenue,

WATERVILle, MAINe, U.S.A.

\section{REFERENCES}

Harrington, D. O. (1951). Amer. J. Ophthal., 34, 1395.

Hill, H. F. (1957). Trans. Amer. Ophthal. Otolaryng., "Cataract Surgery", Instructional Section, Course No. 16T.

NiRANKARI, M. S., and Maudgal, M. C. (1957). Brit. J. Ophthal., 41, 487.

\section{BOOK REVIEWS}

The Effect on Binocular Vision of Variations in the Relative Sizes and Levels of Illumination of the Ocular Images. By H. F. Gillotr. 1957. Pp. 82, 34 figs, 50 refs. British Optical Association, London. (50s.)

When your reviewer discussed irradiation aniseikonia with the late Lord Charnwood, a few sporadic measurements showed that if it existed at all it must be a negligible effect. 
This was, however, a somewhat glib conclusion. The only thing which can be questioned was the occurrence of irradiation: if this obtains, conditions for anomalous stereopsis exist. In an exhaustive study dealing with this and related topics, Gillott has shown that the effect indubitably exists, but that, under his conditions, it is small. His monograph covers the subject adequately from both an experimental and a theoretical point of view. His experiments were done on a large number of observers and are carefully analysed. A minor criticism refers to the amateurish lettering in the otherwise excellent figures, which detracts from the extrinsic neatness of the work, though not from its intrinsic value and interest.

Atlas of Eye Surgery. By R. T. Paton, H. M. Katzin, and D. Stilwell. 1957. Pp. 248, 463 diagrams. McGraw-Hill, London. (£5 12s. 6d.)

The purpose of this atlas is to show the resident eye surgeon a basic technique which has as its aim safety in eight groups of eye operations: cataract, glaucoma, retinal detachment, corneal transplantation, enucleation, evisceration, squint, and pterygium. The authors have treated their matter admirably. The illustrations are excellent black-andwhite line drawings which show clearly each step of an operation as seen by the operatorthat is from above and behind the patient's head. These illustrations are clearly drawn and excellently designed and arranged to convey a pictorial sequence of the operative steps. The authors have indeed achieved their purpose.

It is hoped that subsequent editions may include operations on the lacrimal apparatus, lids, and orbit.

There is little to criticize. In the performance of iridocapsulotomy it is generally preferable to penetrate the iris and capsule with a stab from von Graefes cataract knife just before its withdrawal rather than to do so with the point of de Wecker's iris scissors as recommended in this book. The opening achieved by this operation is drawn as a triangle, but generally the triangular cut pupil becomes circular or almost so. The drawings of the diathermy operation and scleral resection for retinal detachment show diathermy applications unnecessarily extensive and wide of the retinal tear, and there is a misprint of $2-3 \mathrm{~cm}$. for $\mathrm{mm}$.

The condemnation of partially-exposed orbital implants is not firm enough.

Resection of the superior oblique is recommended as an alternative to pleating, but many surgeons would consider that the danger of resecting the long expanded tendon of this muscle is that the sutures may come asunder.

This atlas is of great value to the young surgeon, for upon the clear directions given by its admirable illustrations he could establish the basis of a sound and safe technique.

The publishers are to be congratulated on the excellence of its production.

\section{Books Received}

The following book has been received and will be the subject of a review in Ophthalmic Literature, 11, No. 3, March, 1958.

Cortisone Therapy: Mainly Applied to the Rheumatic Diseases. By J. H. GLYN. 1957. Pp. 162, bibl. Heinemann, London. (21s.)

\section{NOTES}

In December, 1957, the Senate of the University of London conferred the title of Professor of Pathology in the University upon Dr. Norman Ashton in respect of his appointment as Director of the Department of Pathology at the Institute of Ophthalmology. 